\title{
8
}
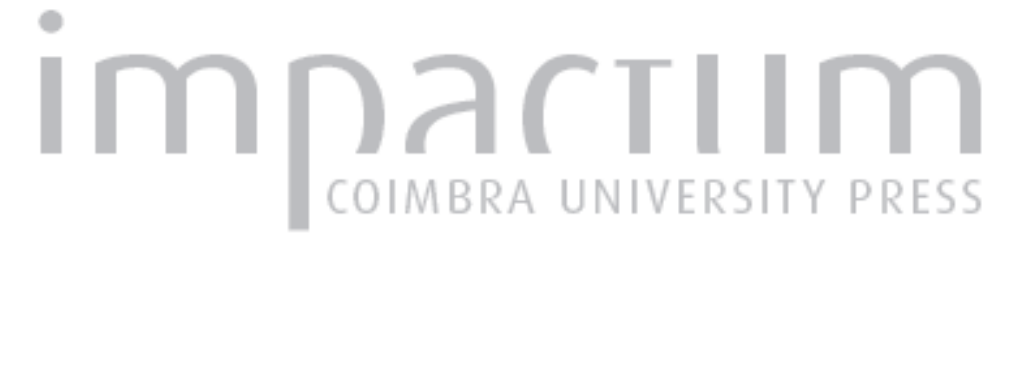

\section{O clima como risco, as cidades como sistemas vulneráveis, a saúde como promoção da vida}

Autor(es): $\quad$ Sant'Anna Neto, João Lima

Publicado por: $\begin{aligned} & \text { Faculdade de Letras da Universidade de Coimbra, Departamento de } \\ & \text { Geografia }\end{aligned}$

URL

persistente:

URI:http://hdl.handle.net/10316.2/30224

DOI:

DOI:http://dx.doi.org/10.14195/0871-1623_31_19

Accessed : $\quad$ 26-Apr-2023 13:05:59

A navegação consulta e descarregamento dos títulos inseridos nas Bibliotecas Digitais UC Digitalis, UC Pombalina e UC Impactum, pressupõem a aceitação plena e sem reservas dos Termos e Condições de Uso destas Bibliotecas Digitais, disponíveis em https://digitalis.uc.pt/pt-pt/termos.

Conforme exposto nos referidos Termos e Condições de Uso, o descarregamento de títulos de acesso restrito requer uma licença válida de autorização devendo o utilizador aceder ao(s) documento(s) a partir de um endereço de IP da instituição detentora da supramencionada licença.

Ao utilizador é apenas permitido o descarregamento para uso pessoal, pelo que o emprego do(s) título(s) descarregado(s) para outro fim, designadamente comercial, carece de autorização do respetivo autor ou editor da obra.

Na medida em que todas as obras da UC Digitalis se encontram protegidas pelo Código do Direito de Autor e Direitos Conexos e demais legislação aplicável, toda a cópia, parcial ou total, deste documento, nos casos em que é legalmente admitida, deverá conter ou fazer-se acompanhar por este aviso.

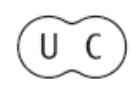




\title{
O clima como risco, as cidades como sistemas vulneráveis, a saúde como promoção da vida
}

\author{
João Lima Sant 'Anna Neto \\ Universidade Estadual Paulista - UNESP. \\ joaolima@fct.unesp.br
}

\section{Resumo:}

Este artigo pretende contribuir para a discussão teórica sobre a relação entre o clima e a cidade numa perspectiva geográfica em que se propõe a possibilidade de se considerar o clima urbano como uma construção social. Por não termos a capacidade de lidar com as grandes catástrofes, por variadas limitações, a humanidade optou por resignar-se aceitando a vulnerabilidade diante dos eventos de grande magnitude. As cidades, como espaços produzidos, ao mesmo tempo em que criam oportunidades civilizatórias, também se transformam em armadilha ambiental. Se a cidade é o habitat da modernidade, se os sistemas urbanos são altamente complexos e desiguais e, se a atmosfera urbana é o produto da interação entre as variáveis do clima e as intervenções socioeconômicas, então os diversos grupos sociais não experimentam nem se relacionam com o tempo e o clima urbano da mesma forma. Nesta perspectiva, tem-se que admitir que o clima urbano possa ser interpretado como uma construção social.

Palavras-chave: Clima urbano. Risco climático. Saúde pública. Produção do espaço.

\section{Résumé:}

Le climat comme risque, les villes comme systèmes vulnérables, la santé comme la promotion de la vie

Cet article vise à contribuer à la discussion théorique à propos de la relation entre le climat et la ville dans une perspective géographique qui propose la possibilité de considérer le climat urbain comme une construction sociale. En considérant qu'on n'a pas la capacité de gérer les catastrophes majeures à cause des limitations, l'humanité a choisi de se résigner à accepter la vulnérabilité aux événements de grande ampleur. Les villes, comme des espaces produits, au même temps de créer des possibilités civilisatrices, deviennent aussi prises au piège environnementale. Si la ville est l'habitat de la modernité, si les systèmes urbains sont très complexes et inégales, et si l'ambiance urbaine est le produit de l'interaction entre les variables climatiques et les interventions socio-économiques, alors les différents groupes sociaux ne connaissent pas ni se rapportent pas à la météo et le climat urbain de la même manière. Dans cette perspective, on doit admettre que le climat urbain peut être interprété comme une construction sociale.

Mots-clés: Climat urbain. Risque climatique. Santé publique. Production de l'espace.

\section{Abstract:}

Climate as risk, cities as vulnerable systems, health as promotion of life

This article aims to contribute to the theoretical discussion about the relationship between climate and the urban space in a geographical perspective that proposes the possibility of considering the urban climate as a social construction. Why not has the capacity to handle major disasters for a variety of limitations, humanity has chosen to resign themselves to accepting vulnerability to events of great magnitude. Cities, as produced spaces at the same time create civilization opportunities also become trapped environment. If the city is the home of modern, if urban systems is highly complex and uneven, and if the urban atmosphere is the product of interaction between climate variables and socioeconomic interventions, then the various social groups do not experience or relate to urban weather and climate of the same way. In this perspective, one has to admit that the urban climate can be interpreted as a social construction.

Keywords: Urban climate. Climate risk. Public health. Production of space. 


\section{Introdução}

Ao longo da história da humanidade as cidades sempre representaram o apogeu da organização social e da sofisticação tecnológica de seu tempo. No mundo antigo, tanto na mesopotâmia como no Egito, as cidades foram uma resposta, entre outros fatores, à situação de risco e vulnerabilidade frente ao abastecimento de água para as atividades agrícolas e abastecimento humano. Daí o fato de geralmente localizarem-se às margens de grandes rios.

As variações do clima, caráter inerente de sua dinâmica, sempre repercutiram fortemente na dispersão e mobilidade dos assentamentos humanos. Entretanto, no passado, a existência de solos ainda não ocupados e os vazios demográficos permitiam que, diante de situações climaticamente extremas, ocorressem migrações para áreas menos vulneráveis.

Eventos climáticos extremos de larga escala temporal, sempre tiveram alguma participação nos processos intrínsecos responsáveis pelo apogeu e queda das grandes civilizações do passado.

Como afirma LAMB (1982), a história da humanidade tem-se desenrolado num mundo de mudanças constantes, por vezes lentas, outras rápidas, e com a natureza das de ciclo longo sempre ofuscada pelos desvios maiores que distinguem os anos individuais. $\mathrm{O}$ ambiente continuará a mudar, em parte devido a intervenções humanas, com as suas conseqüências intencionais ou involuntárias, e em parte devido a causas naturais. Não há nisto seguramente qualquer razão para pensar que, a médio e longo prazo, seja possível prever os acontecimentos futuros.

Desta forma, os acontecimentos do passado histórico e geológico, influenciados pela relação entre clima e civilização assumem importância significativa, como experiências que demonstram como os diversos grupos sociais lidaram com os cataclismos climáticos.

À medida que a ocupação humana avançou e distribuiu-se por praticamente todo o planeta, a possibilidade do deslocamento, quando do impacto de eventos extremos, tornou-se cada vez mais difícil e economicamente inviável. Como afirma FAGAN (2007), o processo de sedentarização nos tem deixado mais fragilizados diante da natureza, pois, independentemente da natureza e dimensão das mudanças climáticas, temos ficado mais vulneráveis e à mercê dos eventos climáticos extremos.

Por não termos a capacidade de lidar com as grandes catástrofes, por limitações tecnológicas, econômicas ou políticas, a humanidade optou por resignar- se aceitando a vulnerabilidade diante dos eventos de grande magnitude (e mais raros), em troca de uma maior capacidade de lidar com as perturbações menores e comuns, como os episódios de chuvas intensas, ou ondas de calor.

Entretanto, nas áreas densamente ocupadas, como nas urbanas, a humanidade ainda não consegue evitar a ocorrência de tragédias com perdas de vidas e de bens materiais, em grande parte porque a gestão do espaço urbano, cada vez mais, escapa ao controle do estado e dos grupos sociais.

A cidade polissêmica da modernidade exige uma ressignificação do conceito de ambiente urbano. As cidades, como espaços produzidos, ao mesmo tempo em que criam oportunidades civilizatórias, também se transformam em armadilha ambiental.

A fixação perene das áreas urbanas e, portanto, a impossibilidade de trasladar as cidades de lugar, nos obriga a repensar a relação sociedade natureza, no sentido de buscar processos e ações adaptativas, que permitam a permanência dos grupos sociais de forma mais estável e, menos suscetível diante dos riscos.

Desta forma, a expansão territorial e a concentração da população mundial nas áreas urbanas, considerando o modo de produção capitalista, têm diminuído a possibilidade de nos fixarmos em novos territórios, ao contrário dos fluxos econômicos, estes sim, globais (Hasbaert e Porto-Gonçalves, 2006).

A cidade, de acordo com o pensamento miltoniano é um sistema de fixos e de fluxos, que se relacionam e se produzem de forma contraditória. Para Santos (2002), estes derivam das intervenções sociais e econômicas no ambiente intra-urbano, por meio das relações entre os agentes sociais.

Entretanto é possível admitir que dentre os tipos de fluxos que atuam no espaço urbano, numa perspectiva ambiental, encontra-se a dinâmica atmosférica e o ritmo climático, que funcionam como forças capazes de agir de forma a pressionar o sistema urbano, ao produzir tipos de tempo que afetam e, não raras vezes condicionam a vida cotidiana das cidades.

Eventos extremos como ondas de calor, chuvas intensas, inundações repentinas, vendavais, elevada amplitude térmica diuturna, tempo seco e estável propício à formação de ilhas de calor, ou concentração de poluentes na atmosfera, são alguns dos exemplos de configurações climáticas que afetam, de forma mais tangente ou mais profunda a economia e a qualidade de vida dos diversos grupos sociais.

Como a produção do espaço urbano segue a lógica da reprodução capitalista, portanto gerador de espaços 
segregados e fragmentados, longe de se produzir um sistema que respeite e se adapte às condições ambientais e naturais, é de se esperar que esta contradição resulte em impactos altamente sensíveis aos diversos grupos sociais que habitam a cidade de forma também desigual, tornando as desigualdades sociais, ainda mais agudas.

Admitindo que, em geral, o equilíbrio entre o sistema urbano e o sistema climático é precário, então quanto maior o desequilíbrio entre estes sistemas, maior a vulnerabilidade urbana, principalmente nas cidades da periferia do mundo desenvolvido, como é o caso das cidades tropicais brasileiras.

Se a cidade é o habitat da modernidade, se os sistemas urbanos são altamente complexos e desiguais e, se a atmosfera urbana é o produto da interação entre as variáveis do clima e as intervenções socioeconômicas, então os diversos grupos sociais não experimentam nem se relacionam com o tempo e o clima urbano da mesma forma.

Espaços desiguais potencializam os efeitos do clima, que se manifestam, também, de forma desigual. Nesta perspectiva, tem-se que admitir que o clima urbano possa ser interpretado como uma construção social.

Se o espaço urbano (os fixos) é uma armadilha, uma presa fácil para a ação dos eventos extremos numa visão fatalista, teríamos que aceitar o fato de estarmos "condenados" à cidade - à cidade enferma, como nos provoca GASPAR (2009). Mas, o espaço urbano também pode ser uma oportunidade (MonTEIRO, 2010), ainda que utópica, de construirmos uma cidade que seja o território da satisfação e da felicidade - a cidade saudável

\section{A vulnerabilidade das cidades frente aos riscos climáticos}

O ambiente urbano é, por definição, complexo e dinâmico. Trata-se do habitat humano por excelência e, como bem afirma RYKWERT (1988), a cidade não é apenas uma solução racional para os problemas de produção, comercialização, circulação e salubridade, mas também, o sujeito que deve preservar e respeitar as esperanças e os temores de seus cidadãos.

Ao mesmo tempo em que o sedentarismo fixou as populações em áreas urbanas, promovendo as enormes possibilidades civilizatórias decorrentes deste processo experimentadas em todos os cantos do planeta, este mesmo fato, torna-se uma armadilha do ponto de vista das relações sociedade natureza, no que concerne à fragilidade dos ambientes urbanos frente aos episódios naturais extremos.

Por mais paradoxal que possa parecer, a cidade que representa o domínio da tecnologia, a organização social e econômica e as formas mais profundas de domínio da natureza, significa também, o aumento da exposição das sociedades urbanas aos riscos naturais (e aos riscos tecnogênicos), tornando-as mais vulneráveis e menos resilientes.

A concentração das edificações, as elevadas densidades demográficas populacionais, a saturação dos sistemas de circulação e a impossibilidade de responder rapidamente aos eventos e episódios extremos, notadamente os de origem meteorológicos, que agridem a integridade urbana, dificultam enormemente as possibilidades de gerenciamento do território por parte da sociedade.

Cada vez mais, episódios menos extremos têm provocado repercussões mais profundas, como as enchentes urbanas, as ondas de calor e a propagação de enfermidades. Assim a perspectiva de enfrentamento destes problemas, deve necessariamente abandonar o conceito de cidade sustentável, pelo da cidade saudável.

O amadurecimento do conceito de cidade saudável sustenta-se, como bem salienta Simões (2007), no reconhecimento da crescente importância da cidade nas sociedades contemporâneas, e da sua abordagem como espaço coletivo, em que múltiplos fatores e determinantes convergem e se inter-relacionam. Os eventos naturais extremos de origem atmosférica são os que mais afetam o espaço urbano, quer em quantidade, quer em intensidade. Enchentes, secas, nevoeiros, geadas, granizos, descargas elétricas, ondas de calor, ciclones tropicais e vendavais, desmoronamentos, deslizamentos de vertentes e ressacas, além dos impactos pluviais concentrados, diariamente afetam milhões e pessoas em todo o mundo.

Quando estes eventos ocorrem em áreas de risco no interior da cidade, a população vulnerável sofre conseqüências que podem variar em grau de intensidade, em função de sua capacidade em enfrentar os desastres.

Cada sociedade e, mais ainda, cada segmento social e, dentro deste cada indivíduo, em particular, distinguem-se por diferentes capacidades e instrumentos disponíveis para enfrentar as catástrofes. 0 poder público, por meio de suas ações e intervenções é o agente responsável pelo ordenamento do território e pela atenção e cuidado com o cidadão, individual e coletivamente. Entretanto, num mundo dominado pelo pensamento neoliberal, cada vez mais, o estado permi- 


\begin{tabular}{|c|}
\hline Atitudes face a um \\
risco com grande \\
probabilidade de \\
ocorrência
\end{tabular}

Figura 1

Atitudes possíveis e prováveis dos diversos grupos sociais com relação a um risco.

Fonte: Monteiro, 1997.

te, incentiva ou, até mesmo delega à participação das corporações do capital, o controle do uso dos espaços, sejam eles públicos ou privados.

Diante do estágio de desenvolvimento econômico e cultural de uma sociedade ou grupo social, a relação destes frente às situações de risco, varia enormemente. Segundo Monteiro (1997), as atitudes em face de um risco podem variar em função da cultura e da história social e política de cada grupo (Figura 1).
O risco, objeto social, é definido por VEYRET (2007) como a percepção do perigo, da catástrofe possível. Ele existe apenas em relação a um indivíduo e a um grupo social ou profissional, uma comunidade, uma sociedade que o apreende por meio de representações mentais e com ele convive por meio de práticas específicas. Na há risco sem uma população ou indivíduo que o perceba e que poderia sofrer seus efeitos. Correm-se riscos, que são assumidos, recusados, estimados, avaliados, cal-

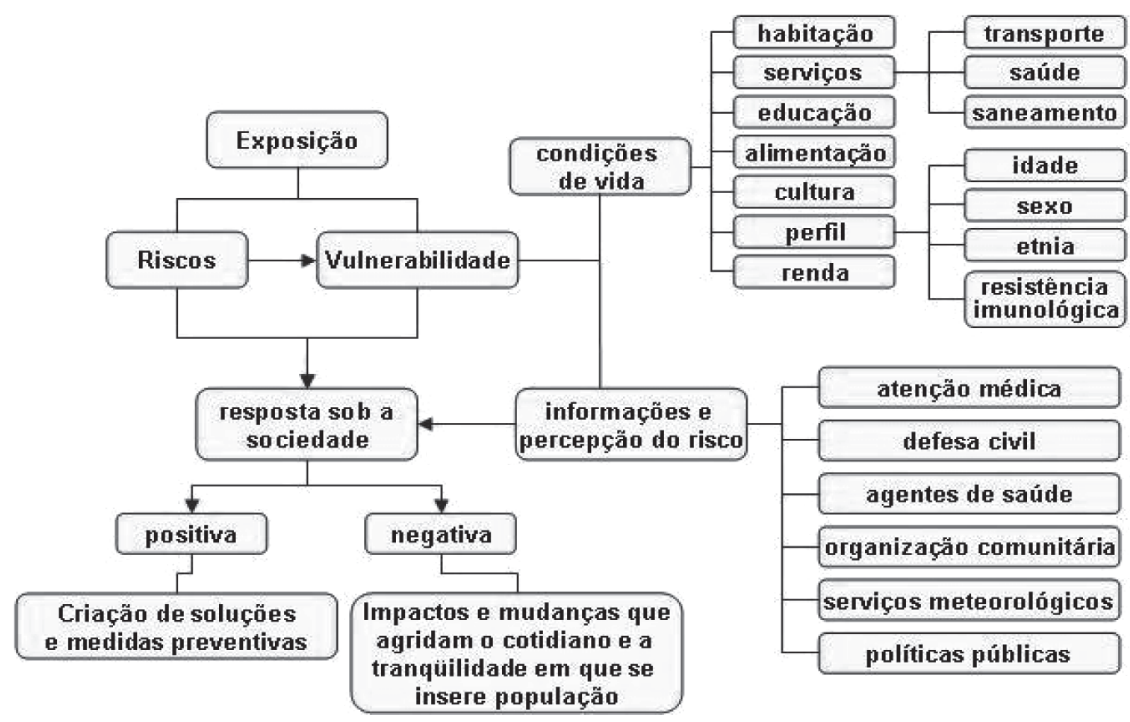

Figura 2

Exposição da sociedade aos riscos e a vulnerabilidade

Fonte: Souza, 2007. 
culados. O risco é a tradução de uma ameaça, de um perigo para aquele que está sujeito a ele e o percebe como tal.

É preciso gerenciar o risco, em sua posição no campo social, variando ao longo do tempo e intensidade. Para isso há a necessidade de enfatizar três tipos de abordagens de ações e medidas: a ação, a informação e a prevenção.

A vulnerabilidade descreve o grau com que um sistema natural ou social é suscetível de suportar ou não os efeitos adversos, considerando o seu nível de exposição, sua sensibilidade e sua capacidade de adaptação (Figura 2).

A vulnerabilidade varia tanto no espaço, quanto no tempo. Essa pode estar inserida em diferentes escalas de análise e de efeito. Em escalas temporais podem se diferenciar entre horas, meses, décadas e até mesmo séculos, e na escala espacial, a graduação dimensional encontra-se entre local (casa, bairro ou cidade), regional (zona ou Estado) e até mesmo em grandes dimensões como nacional ou continental, chegando a nível global.

Os fatores socioeconômicos, em razão da vulnerabilidade, podem aumentar e gerar um quadro muito mais agravado junto às populações que se encontram ameaçadas ou já envolvidas por um risco. De acordo com VEYRET (2007), a vulnerabilidade se mede pela estimativa dos danos potenciais que podem afetar um alvo, tal como o patrimônio construído ou população. Pode ser compartilhada por um grupo social (probabilidade anual de um conjunto de indivíduos ser morto em razão do mesmo acontecimento), ela é, então, função em grande medida, da distribuição da população em torno do local de risco.

No contexto do papel do clima como fonte geneticamente importante de episódios extremos geradores de catástrofes, os produtos resultantes das ações socioambientais no sistema climático são perceptíveis de modo mais eficiente nas áreas urbanas e se expressam por meio dos canais de percepção humana, conforme proposto por MonTEIRO (1976): o termodinâmico (conforto térmico), o físico-químico (qualidade do ar) e o hidrometeórico (impacto pluvial), que se manifestam em eventos já corriqueiros nas metrópoles, como poluição do ar, alterações na ventilação, configurações de ilhas de calor, desconforto térmico, impacto pluvial extremo dentre outros.

A manifestação menos visível deste processo é a ocorrência de enfermidades. Ao contrário de inunda-

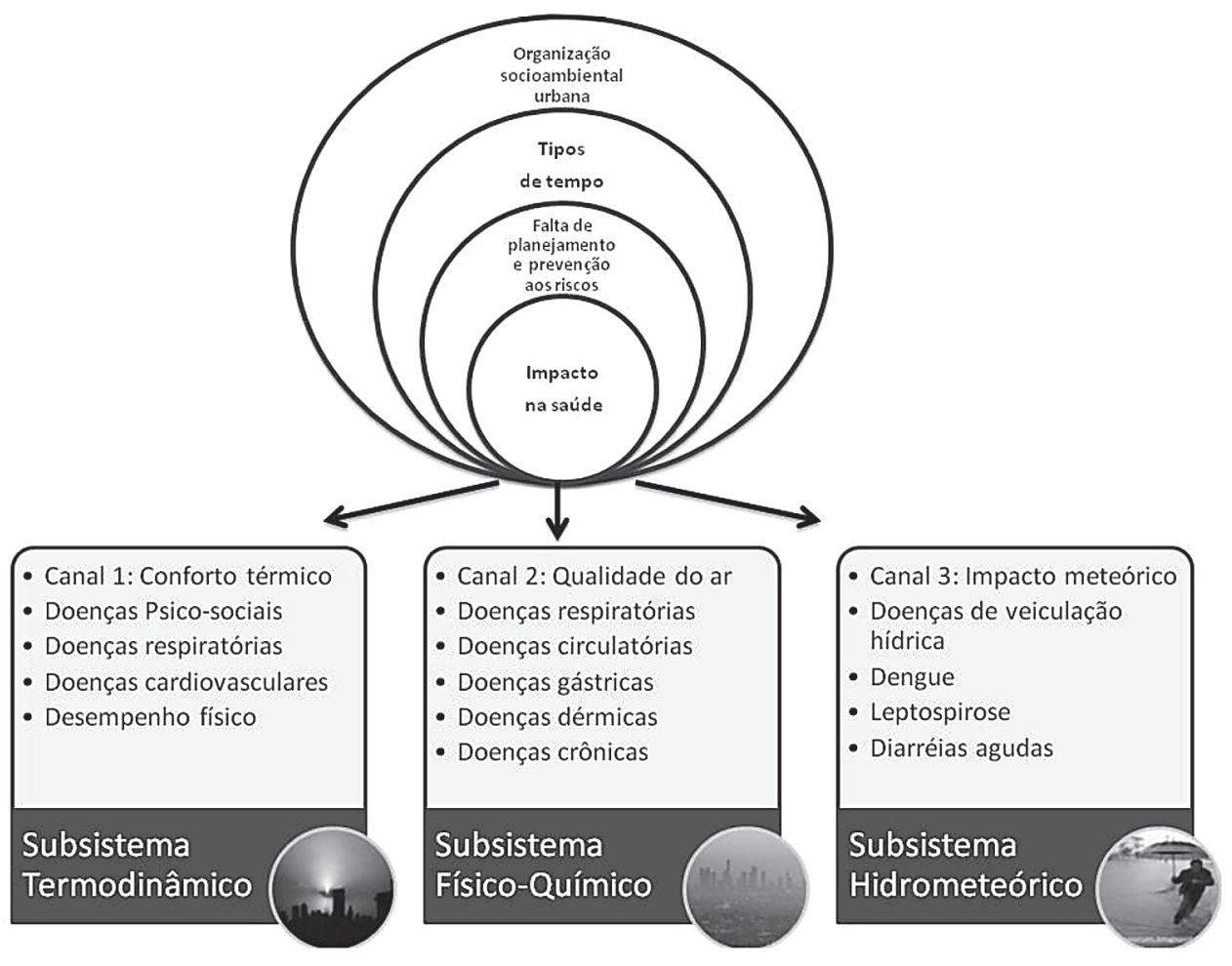

Figura 3

Sistema clima urbano

Fonte: (Monteiro, 1976) Org. Aleixo, 2010. 
ções ou secas, facilmente percebidas, as doenças geradas ou potencializadas por eventos extremos são uma grave ameaça à população urbana. Portanto é difícil dissociar os atributos climáticos da qualidade ambiental e do conforto e bem estar, visto que são componentes do sistema urbano, inteiramente relacionados e dependentes entre si (Monteiro, 1976) (Figura 3).

Várias são as dimensões interpretativas de como o Sistema Clima Urbano (SCU) se relaciona e afeta a população das cidades, mas, sem dúvida é na dimensão da saúde pública que se encontram os indicadores mais significativos do estágio de equilíbrio/desequilíbrio entre os processos naturais e as intervenções sociais na produção do espaço urbano. Trata-se, pois, de um dos principais quesitos utilizados para a definição do estágio de integridade ambiental, humana, econômica e cultural, que definirá a cidade como enferma ou saudável.

De acordo com Aleixo (2011), as relações entre o clima e a saúde perpassam pela qualidade dos condicionantes socioambientais urbanos. Cada clima local de cada cidade em particular apresenta certo grau de variabilidade, que o torna mais regular, ou mais extremado. As áreas urbanas encontram-se, também, em estágios variados de organização e gestão territorial, que oferecem maior ou menor possibilidade dos eventos extremos produzirem situações críticas e calamidades.
Além disto, a gestão dos serviços de saúde assume papel fundamental, ao permitir o acesso da população afetada com rapidez e qualidade, além de adotar com eficiência sistemas de prevenção (Figura 4).

Nas cidades brasileiras, as principais enfermidades que se associam diretamente aos eventos extremos do clima, são as de veiculação hídrica (leptospirose, dengue, doenças diarréicas), que dependem da quantidade e da forma de disposição da água no sistema urbano. Além destas, as doenças respiratórias, que são agravadas por conta da permanência de material particulado (PM10) e gases provenientes da queima de combustíveis fósseis no ambiente urbano, principalmente em dias de tempo estável e seco.

Nos casos de cidades de menor porte, localizadas no interior do Brasil, as doenças do aparelho circulatório também são agravadas em episódios de elevadas temperaturas, nas denominadas ondas de calor.

Entretanto, o grau de vulnerabilidade dos diversos grupos sociais às enfermidades depende de uma série de indicadores, que vão desde as características individuais de cada organismo humano, passando pelas condições sociais e ambientais a que estes indivíduos estão submetidos. Na figura 05, a seguir, demonstra-se uma proposta metodológica para estudos de clima e saúde em ambiente urbano, na perspectiva do conceito de cidade saudável.

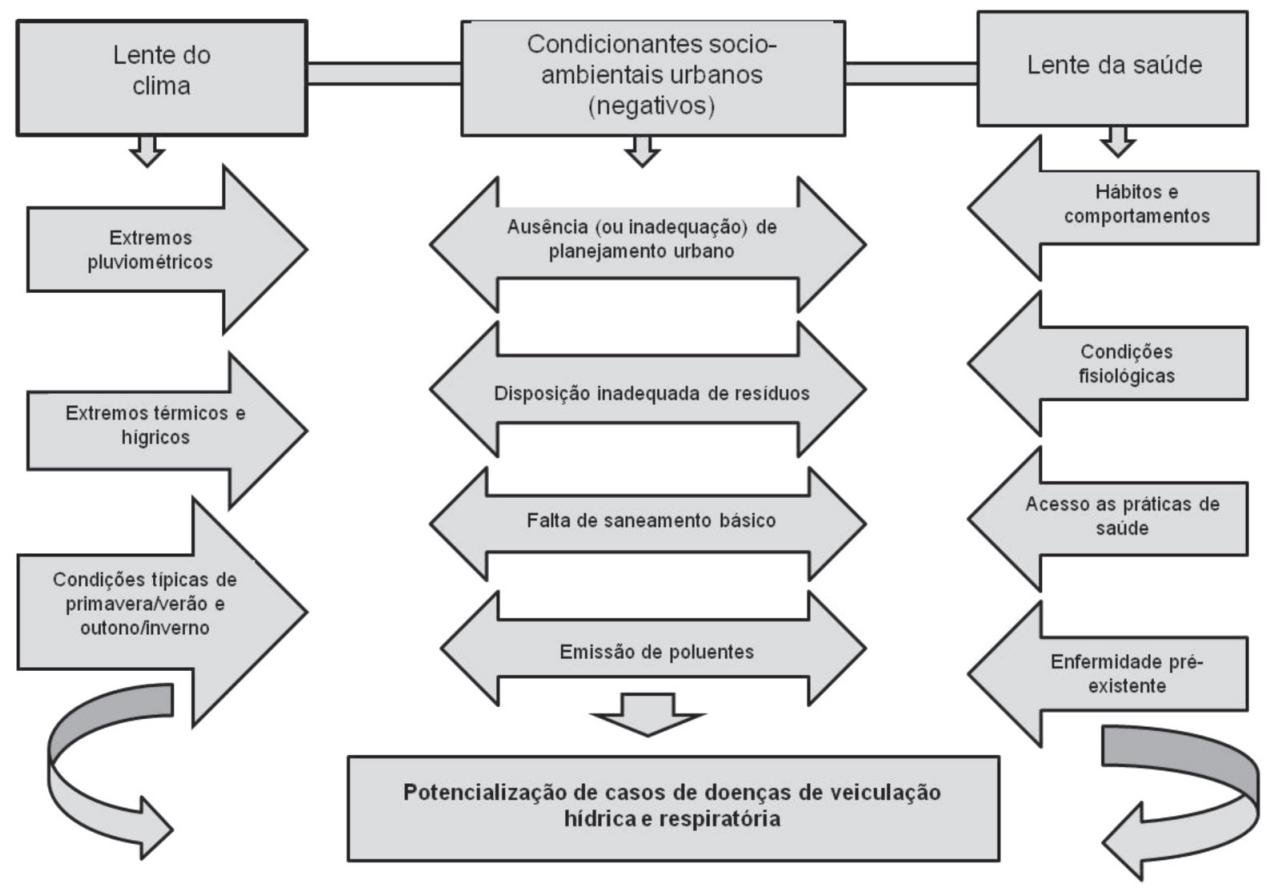

Figura 4

Relação clima e saúde como potencializadora de enfermidades Org. Aleixo, 2011. 


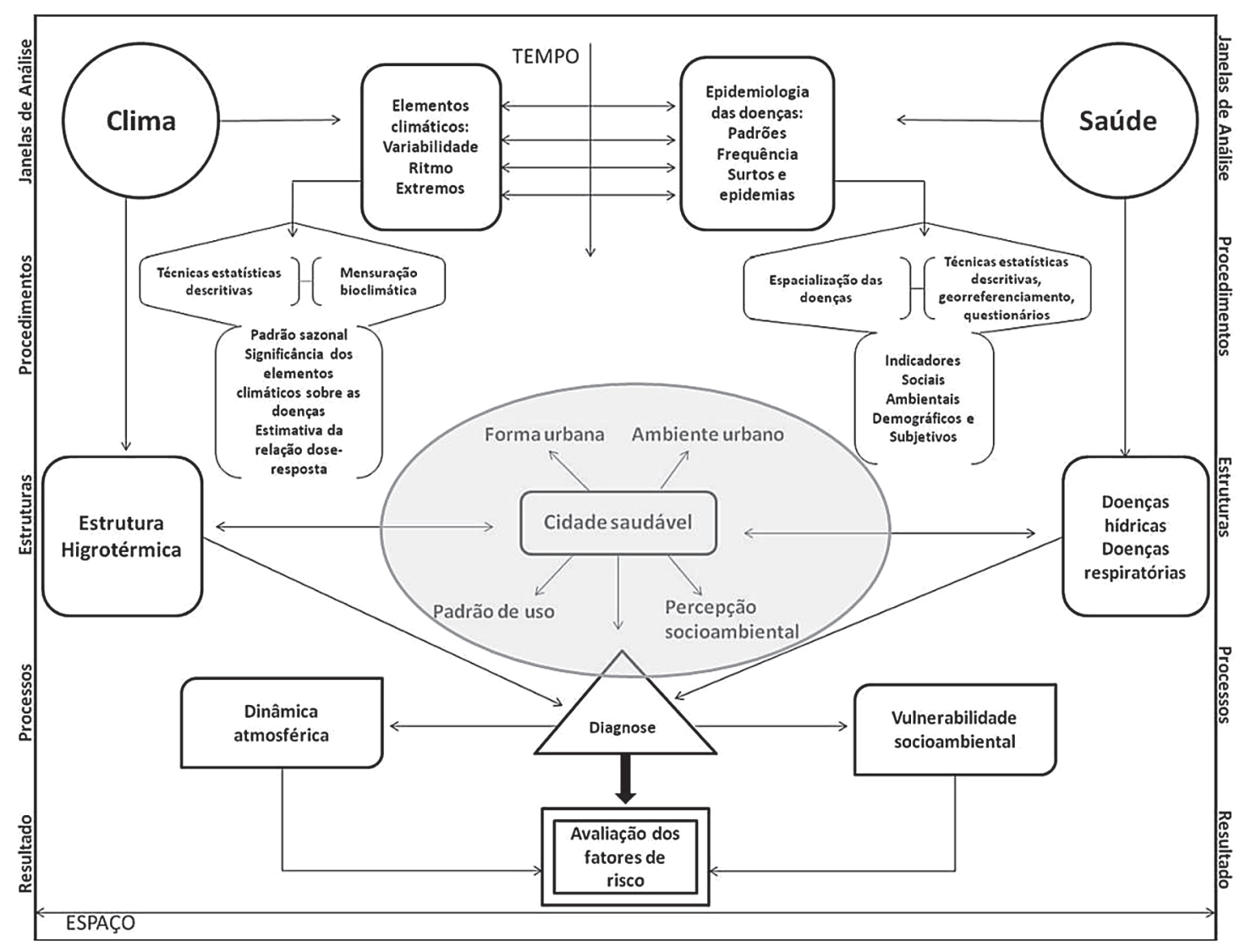

Figura 5

Esquema metodológico da relação clima e saúde em ambiente urbano.

Org. Aleixo; Sant'Anna Neto, 2011.

\section{O sistema clima urbano}

\section{Aspectos termodinâmicos e o (des)conforto térmico}

A expansão territorial urbana caracteriza-se pelo aumento das áreas edificadas e pavimentadas que geram inércia térmica e a produção de calor. As ilhas de calor não causam apenas desconforto térmico em ambientes de clima tropical, mas são responsáveis também, pelo aumento da demanda por energia e pela formação de ambientes urbanos insalubres que afetam a saúde humana.

As coberturas (telhado) são as principais responsáveis pelo calor produzido tanto no interior quanto no entorno das edificações. Este calor é determinado pelas variáveis de albedo (refletância) e emissividade dos materiais. 0 albedo representa a porção da radiação solar incidente, que é refletida pelo material, enquanto a emissividade determina o desempenho térmico caracterizado pela temperatura superficial.
Assim, superfícies com elevado albedo e emissividade tendem a permanecerem mais frias quando expostas à radiação solar, pois absorvem menos radiação e emitem mais radiação térmica para o espaço, transmitindo menos calor para seu entorno. Ao contrário, quanto menor for o albedo e a emissividade maior será a absorção de calor e sua permanência no ambiente de entorno.

Diversos tipos de materiais construtivos têm sido utilizados nas edificações em áreas urbanas. No interior paulista prevalece o uso de três tipos de materiais de cobertura: as telhas cerâmicas, as de fibrocimento e as metálicas (alumínio, aço galvanizado). As coberturas cerâmicas são mais utilizadas em residências de classe média e alta, as de fibrocimento prevalecem nos bairros e conjuntos habitacionais de população de baixa renda e as metálicas nas edificações comerciais e industriais.

Em função de suas propriedades físicas, os materiais de cobertura apresentam as seguintes respostas térmicas (Ferreira e Prado, 2003). 
Quadro I

Temperatura superficial dos materiais (ASTM E 1980-98)

\begin{tabular}{|l|c|c|c|c|}
\hline \multicolumn{1}{|c|}{ Material } & $\begin{array}{c}\text { Albedo } \\
(\mathrm{a})\end{array}$ & $\begin{array}{c}\text { Emissividade } \\
(\mathrm{e})\end{array}$ & $\begin{array}{c}\text { Temperatura } \\
\text { Superficial } \\
\left({ }^{\circ} \mathrm{C}\right)\end{array}$ & $\begin{array}{c}\text { Diferença de } \\
\text { Temperatura } \\
\text { entre o ar e o material }\end{array}$ \\
\hline $\begin{array}{l}\text { Cerâmica } \\
\text { Vermelha }\end{array}$ & 0,53 & 0,9 & 36,8 & $-0,1$ \\
\hline Cerâmica Branca & 0,54 & 0,9 & 36,2 & $-0,6$ \\
\hline Fibrocimento & 0,34 & 0,9 & 47,1 & $+10,3$ \\
\hline Alumínio s/pintura & 0,57 & 0,05 & 69,4 & $+32,6$ \\
\hline Alumínio cores claras & $\begin{array}{c}\text { de } 0,40 \\
\mathrm{a} 0,47\end{array}$ & 0,9 & $\begin{array}{c}\text { de } 40,1 \\
\mathrm{a} 43,3\end{array}$ & $\mathrm{De}+3,2 \mathrm{a}+6,5$ \\
\hline Alumínio cores escuras & $\begin{array}{c}\text { de } 0,26 \\
\mathrm{a} 0,38\end{array}$ & 0,9 & $\begin{array}{c}\text { de } 45,0 \\
\mathrm{a} 51,4\end{array}$ & De + 8,1 a + 14,5 \\
\hline Aço galvanizado sem pintura & 0,57 & 0,25 & 57,9 & 21,1 \\
\hline
\end{tabular}

O resultado desta interação entre a radiação (balanço de energia) e o espaço construído é um dos fatores que determinam o aquecimento da atmosfera urbana. Em cidades de médio porte do oeste paulista, segundo Sant'Anna Neto (2010), este processo tem provocado uma elevação da temperatura que pode ser verificado pelo aumento do número de dias quentes e diminuição dos dias frios. A Figura 06, a seguir, demonstra que o total anual de dias cujas máximas foram iguais ou superiores a $30^{\circ} \mathrm{C}$ subiu de 150 para mais de 200 , entre o final da década de 1960, quando comparado ao período posterior a 2000. Por outro lado, o total anual de dias frios, caiu de 80 a menos de 50 , no mesmo período.

0 stress térmico não causa apenas desconforto, mas é responsável também, pela formação de ambien- tes urbanos insalubres que afetam a saúde humana. Os materiais construtivos são os principais responsáveis pelo calor produzido tanto no interior quanto no entorno das edificações. A população de risco (idosos), em geral, permanece entre 10 e 14 horas diárias em suas residências.

Segundo o Datasus (2010), para as cidades de porte médio do oeste paulista, cerca de $26 \%$ da mortalidade e $24,5 \%$ da morbidade hospitalar (internações) da população compreendida na faixa etária com mais de 50 anos, tem como causa, enfermidades do aparelho circulatório. Isto se deve, em boa parte, em função da população de baixa renda, impossibilitada de adquirir materiais construtivos mais adequados e viver em áreas de pior qualidade ambiental (presença de áreas verdes,

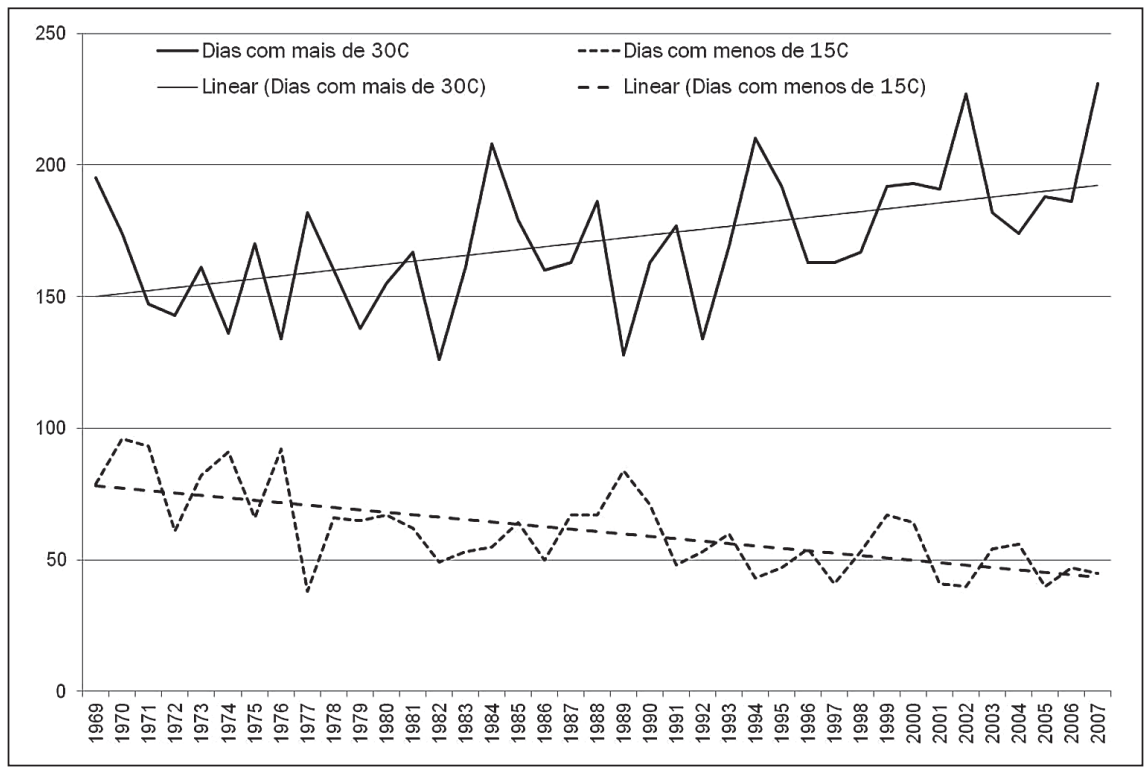

Figura 6

Número de dias quentes e frios em Presidente Prudente, entre 1969 e 2007.

Fonte: Estação Meteorológica de Presidente Prudente. 
existência de equipamentos de (aser, etc.), é a mais prejudicada pelos efeitos adversos do calor armazenado nas edificações.

No interior paulista, na maior parte dos dias de primavera e verão, as temperaturas diurnas do ar oscilam entre $30^{\circ} \mathrm{C}$ e $35^{\circ} \mathrm{C}$ que somadas ao calor produzido e armazenado pelas coberturas de fibrocimento, podem superar os $45^{\circ} \mathrm{C}$, expondo a população, notadamente os idosos, a situações de insalubridade que se manifestam na forma de enfermidades do aparelho circulatório. Assim, o clima também se constitui em importante fator de qualidade de vida e indicador de justiça social.

Impactos hidrometeóricos: enchentes, inundações e as enfermidades decorrentes

No mundo tropical, as chuvas (ou a sua ausência) assumem papel de protagonista, como agente impactante na integridade do sistema urbano. Historicamente, as cidades do centro-sul do Brasil recebem precipitações da ordem de 1200 a $1800 \mathrm{~mm}$ anuais. Cerca de $70 \%$ deste total, ocorrem no período de primavera/ verão.

A expansão territorial verificada na maior parte dos centros urbanos, ao longo do século XX, foi responsável pela total negligência com relação à topografia e a rede de drenagem, permitindo a ocupação humana em fundos de vale, planícies de inundação ou nas encostas íngremes, que se destacam como áreas potencialmente palco dos riscos.

A lógica da reprodução capitalista, que define o preço da terra nas cidades, obriga os grupos sociais menos favorecidos a ocuparem as áreas de maior risco, expondo-os à situação de vulnerabilidade. Esta combinação entre população vulnerável habitando áreas de risco apresenta outro ingrediente problemático, que é a ausência da assistência por parte do poder público e a falta de ações preventivas que possam minimizar os seus impactos. Assim, constroem-se as situações ou episódios que levam às catástrofes.

Cada vez mais, episódios de chuvas intensas de menor proporção são capazes de promover mais situações de emergência ou calamidades. Isto, porque a perda de capacidade do poder público em gerenciar e controlar o espaço urbano permite que as ocupações irregulares e as intervenções inadequadas sobre o ambiente, desequilibrem o já frágil equilíbrio socioambiental do tecido urbano.

Como o modo de produção capitalista territorializa distintas formas de uso e ocupação do espaço, o efeito dos tipos de tempo sobre um espaço construído de maneira desigual gera problemas de origem climáti- ca, também, desiguais. A entrada de um sistema atmosférico, como uma frente fria (frente polar atlântica), por exemplo, se espacializa de maneira mais ou menos uniforme num determinado espaço, em escala local. Entretanto, em termos socioeconômicos, este sistema produzirá diferentes efeitos em função da capacidade (ou possibilidade) que os diversos grupos sociais têm para defenderem-se de suas ações.

Se o resultado concreto da entrada desta frente fria, em área urbana, for a queda de precipitação em grandes quantidades, e se o produto final desta ação desembocar numa enchente, tem-se que admitir que muito provavelmente as áreas mais atingidas pelas águas deverão ser aquelas onde os equipamentos urbanos e o poder público funcionam de forma mais precária, pois as enchentes não atingem e não afetam a todos da mesma maneira (SAnT'Anna Neto, 2012).

Nesta perspectiva, a vulnerabilidade é um conceito relativo, pois é resultado mais da capacidade de um indivíduo, ou grupo social de defender-se ou superar o impacto causado por um evento extremo, do que a forma e intensidade de ocorrência do evento em si (Bicknell; Dodman e Satterthwaite, 2009).

As enchentes e inundações ocorrem devido a duas ordens de fatores: a intensidade das chuvas e a capacidade de escoamento das águas superficiais. 0 escoamento das águas pluviais depende da integridade do sistema de drenagem e, principalmente, do uso e ocupação do solo na bacia de drenagem.

$\mathrm{Na}$ maior parte das cidades tropicais do centrosul do Brasil, muitos dos episódios de chuvas intensas não resultariam em enchentes e inundações, se as intervenções sobre o território considerassem a dinâmica natural do clima, permitindo que houvesse fluidez do escoamento da água, permeabilidade do solo, áreas verdes e menor concentração de áreas construídas (AмоRIM, 2000).

Como o espaço urbano é fragmentado e segregado, os bairros de média e alta renda, onde a estrutura urbana é mais adequada, as chuvas provocam problemas que afetam a mobilidade principalmente do trânsito, gerando algumas perdas econômicas.

Nas áreas de baixa renda, as perdas materiais envolvem, muitas vezes o que a família pode acumular durante anos, como eletrodomésticos, móveis, etc. Além disto, com a permanência da água durante um longo período manifestam-se as enfermidades.

A água que permanece no sistema urbano tornase foco de proliferação de insetos e fonte potencial de enfermidades de veiculação hídrica, como a leptospirose, as doenças diarréicas. Segundo estudo realiza- 
do em Ribeirão Preto por Aleixo (2011), a leptospirose associa-se mais a falta de infra-estrutura urbana e vulnerabilidade social, do que com a quantidade ou intensidade das chuvas. Na Figura 7, observa-se que os casos de leptospirose ocorrem em áreas de risco próximas a córregos urbanos pouco saneados e sujeitos a inundação, por causa da canalização e ocupação de suas margens.

Os estudos de Costa (2001), em Paranavaí, de DAMASCENo (2008), sobre Santos e de Aleixo (2011), a respeito de Ribeirão Preto, demonstram que a prolifera- ção do inseto e o aumento dos casos de dengue, não apresentam correlação linear direta com o aumento das chuvas, mas, sim, com a disponibilidade de reservatórios de água em áreas vulneráveis e precariedade do sistema de saúde.

Assim como os efeitos adversos do sistema termodinâmico nas áreas urbanas, os eventos extremos derivados dos impactos meteóricos devem ser considerados na perspectiva da produção do espaço urbano e do grau de vulnerabilidade que os diversos grupos sociais estão expostos.

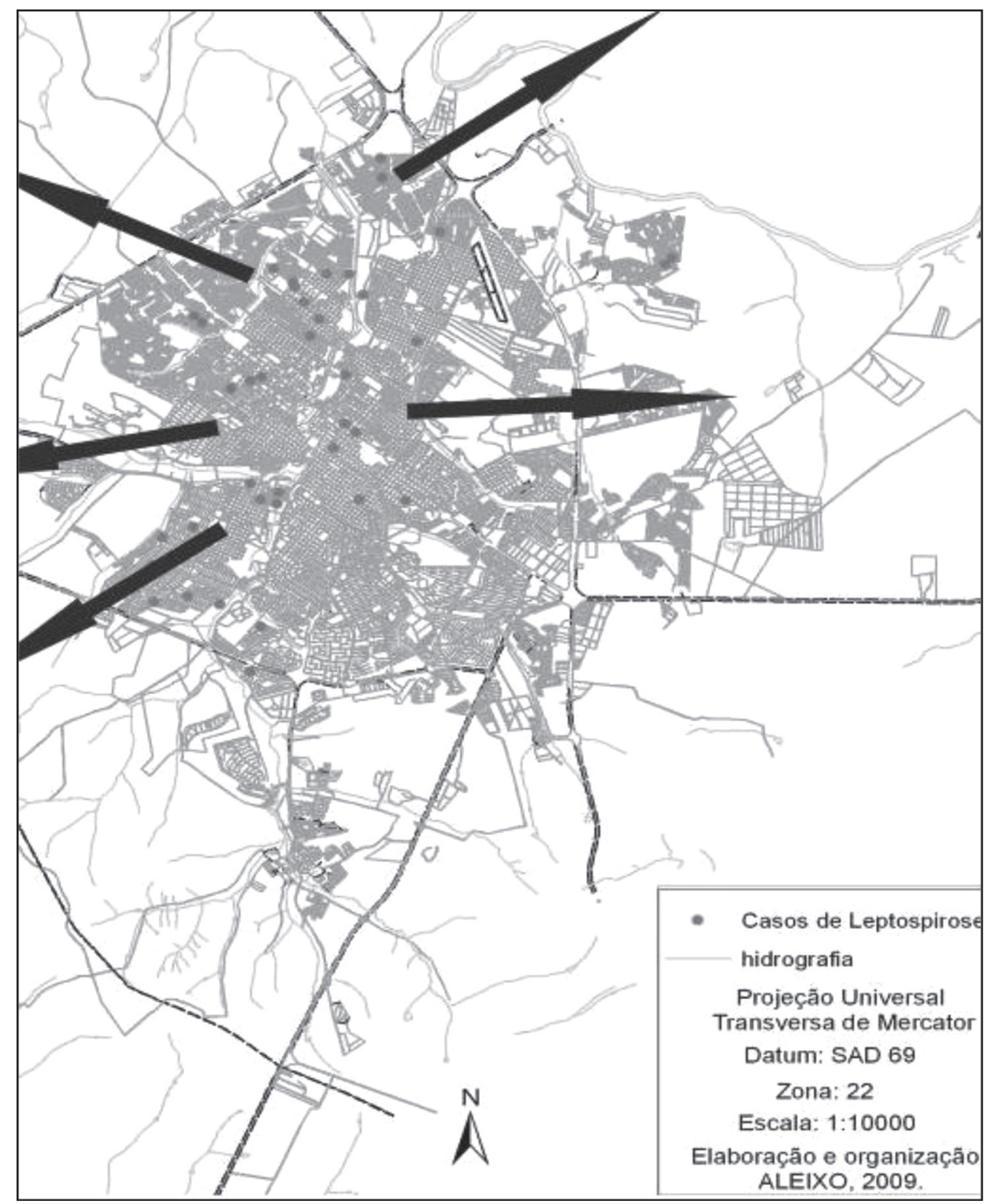

Figura 7

Ocorrência de casos de leptospirose em Ribeirão Preto.

Fonte: Aleixo, 2011. 


\section{O sistema físico-químico e a qualidade do ar}

A atmosfera urbana é o resultado da interação entre sua composição original e as emissões de gases e partículas provenientes do processo de produção do espaço. Dependendo dos tipos de tempo atuantes, tanto a temperatura quanto a umidade podem potencializar efeitos positivos e/ou negativos à qualidade do ar.

Se originariamente a atmosfera natural, na baixa troposfera, é composta por cerca de 78\% de nitrogênio, $21 \%$ de oxigênio e $1 \%$ de outros gases, nas áreas urbanas as fontes de emissão de poluentes, podem modificar drasticamente esta composição, em função do modelo de transporte, da localização e tipos de indústrias e da existência de sumidouro de gases indesejáveis.

A expansão territorial urbana da região metropolitana de São Paulo apresenta características típicas de outras jovens metrópoles do mundo tropical: a) rápido crescimento demográfico, passando de pouco mais de 200.000 habitantes no início do século XX, para 20 milhões em 2010; b) aumento significativo da frota e expansão da rede viária que privilegia o uso individual de veículos leves e corredores de ônibus coletivos; c) grande concentração de poluentes atmosféricos decorrentes da queima de combustíveis fósseis provenientes do uso de gasolina e óleo diesel.

A localização geográfica da área urbana da metrópole, no trópico de capricórnio numa bacia sedimentar a 750 metros de altitude e a $70 \mathrm{~km}$ do litoral, confere a esta região de clima tropical de altitude, um caráter peculiar de condições desfavoráveis à dispersão dos poluentes. Estima-se que em cerca de $70 \%$ dos dias do ano a qualidade do ar encontra-se desfavorável.

De acordo com a Companhia de Saneamento Ambiental (CETESB, 2011), a qualidade do ar é considerada inadequada quando a concentração de material particulado supera $150 \mu \mathrm{g} / \mathrm{m} 3$, o CO maior do que $9 \mathrm{ppm}$, o $\mathrm{NO} 2$ maior do que $320 \mu \mathrm{g} / \mathrm{m} 3$ e o SO2 maior do que 365 $\mu \mathrm{g} / \mathrm{m} 3$ (Quadro II).

Com uma frota de 6 milhões de veículos circulando principalmente no centro expandido da cidade de São Paulo, as emissões de poluentes geram efeitos adversos que se manifestam com maior intensidade em crianças, idosos e indivíduos portadores de doenças crônicas, principalmente sobre os segmentos mais desfavorecidos do ponto de vista socioeconômico.

De acordo com os dados mais recentes sobre a mortalidade em São Paulo, em 2005, cerca de 27\% das 85.982 mortes estão relacionadas às doenças do aparetho respiratório e destas, $42 \%$ ou cerca de 7.000 mortes por ano, são causadas pelas emissões provenientes da queima de combustíveis fósseis, principalmente pela presença do enxofre proveniente do óleo diesel (Sant'Anna Neto, 2010).

Estimativas recentes do Departamento de Trânsito (DETRAN, 2011) para o município de São Paulo calculam em cerca de 6,8 milhões de veículos circulando diariamente. Destes, aproximadamente $72 \%$ são automóveis de passageiros, ou seja, emissores de material particulado e monóxido de carbono. Entretanto, das 24 milhões de viagens diárias realizadas pela população paulistana, 18 milhões são efetuadas por transporte coletivo (ônibus, metro, trem) ou a pé.

Isto significa que a poluição é gerada por uma pequena parcela da população (proprietários de automóveis), mas os seus efeitos negativos afetam toda a população, principalmente os pedestres que são obrigados a respirar o ar contaminado nas vias públicas.

Para se ter uma idéia da dimensão do problema, são apresentados na Figura 8 dados sobre a mortalidade por doença respiratória na cidade de São Paulo, em 2005.

Em função da forte segregação socioespacial da população urbana, este quadro revela uma situação em que os que mais sofrem com os efeitos adversos da poluição são aqueles que menos contribuem para a emissão dos poluentes, caracterizando um contexto de injustiça ambiental e exclusão social.

\section{Da cidade enferma à cidade saudável}

Nos últimos 50 anos o crescimento populacional das áreas urbanas em todo o planeta é impressionante. Em 1950, cerca de 737 milhões de habitantes $(29,1 \%)$ viviam em cidades. Os dados para 2010 apontam para

Quadro II

Padrão de qualidade do ar segundo a CETESB, 2011

\begin{tabular}{|c|c|c|c|c|c|}
\hline Qualidade do ar & PM10 $(\mu \mathrm{g} / \mathrm{m} 3)$ & O3 $(\mu \mathrm{g} / \mathrm{m} 3)$ & $\mathrm{CO}(\mathrm{ppm})$ & $\mathrm{NO2}(\mu \mathrm{g} / \mathrm{m} 3)$ & $\mathrm{SO2}(\mu \mathrm{g} / \mathrm{m} 3)$ \\
\hline Boa & $0-50$ & $0-80$ & $0-4,5$ & $0-100$ & $0-80$ \\
\hline Adequada & $50-150$ & $80-160$ & $4,5-9$ & $100-320$ & $80-365$ \\
\hline Inadequada & $150-250$ & $160-200$ & $9-15$ & $320-1130$ & $365-800$ \\
\hline Ruim & $250-420$ & $200-800$ & $15-30$ & $1130-2260$ & $800-1600$ \\
\hline Péssima & $>420$ & $>800$ & $>30$ & $>2260$ & $>1600$ \\
\hline
\end{tabular}




\section{Cálculo da mortalidade relacionada ao diesel}

- OMS indica um ganho de $0,6 \%$ das mortes naturais em adultos com mais de 30 anos para cada incremento de $1,0 \mu \mathrm{g} / \mathrm{m} 3$ de material particulado.

\ São Paulo: 2005 (adultos maiores que 30 anos)

๑ 85,982 mortes por causas naturais

a 6,923 mortes por doenças respiratórias causadas por PM10 emitido pelo diesel

6. Custo estimado da mortalidade

- De posse destas projeções de mortalidade, é possível estabelecer-se uma estimativa grosseira dos custos financeiros da poluição por veículos diesel nas 6 capitais avaliadas.

Caso consideremos o menor valor estatístico da vida humana em países em desenvolvimento - US $\$ 512.000,00$ - o custo anual da poluição por veículos diesel nas cidades estudadas é da ordem de US $\$$ 5 bilhões (cinco bilhões de dólares) ao ano.

\section{Figura 8}

Cálculo da mortalidade por doenças respiratórias associadas à presença de material particulado na cidade de São Paulo em 2005

Fonte: Sant'Anna Neto, 2010

mais de 3,5 bilhões de seres humanos morando em áreas urbanas, ou seja, aproximadamente $50,6 \%$ da população mundial.

Estes dados são ainda mais significativos, quando se observa o Quadro III, a seguir, com respeito a distribuição desta população entre as áreas urbanizadas dos países mais ricos e dos mais pobres, que apresentam maior vulnerabilidade.

A ocorrência dos tipos de eventos e desastres climáticos nas áreas urbanas é bastante variada, porém, é possível distinguir dois grandes grupos. De um lado, estão as cidades que são afetadas por processos de elevada magnitude, contra a qual, mesmo no atual estágio de desenvolvimento tecnológico, pouco há a fazer, a não ser, buscar medidas de prevenção para minimizar seus impactos. São as cidades localizadas em áreas em que o nível do mar está subindo, ou aquelas afetadas por ciclones tropicais.
Por outro lado, a maior parte das áreas urbanas localiza-se em regiões em que os fenômenos climáticos atuantes são sazonais ou interanuais, de magnitude menor que propicia medidas mitigatórias de adaptação e interferência humana na resolução ou na minimização de seus impactos. É o caso das cidades que sofrem com enchentes, inundações, secas, ondas de calor ou de frio.

Nestas cidades, a vulnerabilidade em que se encontra grande parte de seus moradores é que agrava o impacto dos eventos extremos, portanto, a natureza do evento é essencialmente social e econômica. Como as áreas urbanas localizadas em países de economia periférica não apresentam estrutura urbana adequada $e$ o poder público não tem o controle do uso do solo, a integridade do sistema urbano fica comprometida, daí o termo - cidades enfermas, pois se tratam de cidades doentes do ponto de vista do desequilíbrio entre o ambiente urbano e as práticas sociais.

A perspectiva utópica de transformá-las em cidades saudáveis passa, em primeiro lugar, pela ação do estado, como planejador, organizador e gestor do espaço urbano, em associação com o poder local e a participação das organizações civis, no processo de reordenamento do território.

As cidades saudáveis não estarão isentas de sofrerem impactos climáticos extremos, porém, as ações mitigatórias, os sistemas de proteção e a prevenção deverão ser eficientes como políticas de bem estar.

Assim como não existe vulnerabilidade natural, tampouco pode haver doenças climáticas. A vulnerabilidade sempre está associada à capacidade dos indivíduos e grupos sociais em lidar com as adversidades, ou seja, aumentando o seu grau de resiliência. Doença climática é um termo infeliz, que sugere uma fatalidade inexorável, externa ao ser humano. Sabe-se que todas

Quadro III

Distribuição da população urbana, por região/continente - 1950/2010

\begin{tabular}{|l|c|c|c|c|c|}
\hline $\begin{array}{c}\text { Região ou continente } \\
\text { Pop. urbana (em milhões de hab.) }\end{array}$ & 1950 & 1970 & 1990 & 2000 & $\begin{array}{c}2010 \\
\text { (projeção) }\end{array}$ \\
\hline Mundo & 737 & 1332 & 2275 & 2854 & 3495 \\
\hline Países desenvolvidos & 427 & 652 & 818 & 873 & 925 \\
\hline Países em desenvolvimento & 310 & 680 & 1456 & 1981 & 2570 \\
\hline Países pobres & 15 & 41 & 110 & 169 & 254 \\
\hline África & 33 & 86 & 204 & 295 & 412 \\
\hline Ásia & 237 & 485 & 1015 & 1373 & 1770 \\
\hline Europa & 281 & 412 & 509 & 520 & 530 \\
\hline América Latina e Caribe & 69 & 164 & 314 & 394 & 471 \\
\hline BRASIL & 19 & 53 & 111 & 143 & 171 \\
\hline América do Norte & 110 & 171 & 214 & 250 & 286 \\
\hline Oceania & 8 & 14 & 19 & 22 & 25 \\
\hline
\end{tabular}

Fonte: Bicknell, Dodman e Satterthwaite, 2009 
as enfermidades, que outrora foram consideradas como fruto do determinismo climático, na atualidade apresentam etiologia conhecida, que o progresso da medicina e o avanço dos serviços de saúde podem controlar e erradicar.

O cerne do problema é o interesse, a vontade e a capacidade dos agentes e atores sociais em transformar os territórios urbanos enfermos em espaços de bem estar e qualidade vida a todos os seus habitantes.

\section{Fontes bibliográficas}

AleIXo, N. C. R. (2011) - Pelas lentes do clima e da saúde. UNESP: Presidente Prudente. Relatório de Pesquisa/FAPESP.

Aleixo, N. C. R e Sant'Anna Neto, J. L. (2011) - "Percepção e riscos: abordagem socioambiental do processo saúde-doença". Mercator, 10(22), Fortaleza, pp. 191-208.

AMorim, M. С. С. T. (2000) - O clima urbano de Presidente Prudente /SP. Tese de Doutorado, Universidade de São Paulo, São Paulo. 374p.

Bicknell, J.; Dodman, D. e Satterthwaite, D. (2009) - Adapting cities to climate change. Earthscan, London.

CETESB, www.cetesb.sp.gov.br. Data de acesso 23/08/2011

CostA, M. A. R. (2001) - A ocorrência do Aedes Aegypti na Região Noroeste do Paraná. Dissertação de Mestrado, Universidade Estadual Paulista, Presidente Prudente.

DAMACENo, A. (2008) - Cidades febris entre a serra e o mar: clima e dengue na área metropolitana da Baixada Santista. Dissertação de Mestrado, Universidade Estadual Paulista, Presidente Prudente.

DATASUS, www.datasus.gov.br. Data de acesso 28/09/2010.

DETRAN, www.detran.sp.gov.br . Data de acesso 27/09/2011

FAGAN, B. (2007) - o longo verão: como o clima mudou a civilização. Edições 70, Lisboa.

Ferreira, F. L. e Prado, R. T. A. (2003) - "Medição do albedo e análise de sua influência na temperatura superficial dos materiais utilizados em coberturas de edifícios no Brasil”. Boletim Técnico da Escola Politécnica da USP $(\mathrm{s} / \mathrm{n})$, São Paulo.

Gaspar, J. (2007) - "Cidade, saúde e urbanização". In: Santana, P. (org.) - A cidade e a Saúde. Almedina, Coimbra, pp. 23-38.
Hasbaert, R. e Gonçalves, C. V. P. (2006) - A nova des-ordem mundial. Editora da UNESP, São Paulo.

Lamb, H. (1982) - Climate, history and the modern world. Routledge, London.

MontelRo, C. A. F. (1976) - Teoria e clima urbano. Instituto de Geografia da Universidade de São Paulo. (Série Teses e Monografias, 25).

Monteiro, A. (2010) - "Climatologia e gestão do território". Conferência de abertura do IX Simpósio Brasileiro de Climatologia Geográfica. ABCLIMA/UFC, Fortaleza.

MontelRo, A. (1997) - O clima urbano do Porto: contribuição para a definição das estratégias de planeamento $e$ ordenamento do território. Fundação Calouste Gulbenkian, Junta Nacional de Investigação Científica e Tecnológica, Lisboa.

RYKWERT, J. (1988) - The idea of a town: the anthropology of urban form in Rome, Italy, and the ancient. MIT Press, Boston.

Sant'Anna Neto, J. L. (2001) - História da Climatologia no Brasil. Tese de Livre Docência, Universidade Estadual Paulista, Presidente Prudente.

Sant'Anna Neto, J. L. (2011) - "O clima urbano como construção social". Revista Brasileira de Climatologia, 7(8), Curitiba, pp. 45-60.

Sant'Anna Neto, J. L. e Amorim, M. C. C. T. (2008) - "Febrile cities: the influence of construction materials in the production of heat islands in low-income districts of urban areas with tropical climate in Brazil". In: Climate Change and Urban Design - The Third International European Urbanism Congress, Oslo.

SANTOS, M. (2002) - A natureza do espaço. Editora da Universidade de São Paulo, São Paulo.

Simões, J. M. (2007) - "Construindo a cidade saudável". In: Santana, P. (org.) - A cidade e a Saúde. Almedina, Coimbra, pp. 39-48.

SouzA, C. G. (2007) - A influência do ritmo climático na morbidade respiratória em ambientes urbanos. Dissertação de Mestrado, Universidade Estadual Paulista, Presidente Prudente.

VeYRet, Y. (2007) - Os riscos. O homem como agressor e vítima do meio ambiente. Editora Contexto, São Paulo. 